\title{
Examining the Credibility of Online Political News and information in the Millennials in Pakistan
}

Faisal Waqas ${ }^{1}$, Dr. Ifra Iftikhar*2 \& Dr. Amir Bajwa ${ }^{3}$

${ }^{1}$ Research Fellow, Superior University, Lahore, Pakistan

${ }^{23}$ Associate Professor, Lahore Garrison University, Lahore, Pakistan

Corresponding Author: Samra Maqbool, E-mail: ifraiftikhar@gmail.com

\section{ARTICLE INFORMATION}

Received: December 17, 2020

Accepted: January 07, 2021

Volume: 3

Issue: 1

DOI: 10.32996/jhsss.2021.3.1.9

\section{KEYWORDS}

Political News, Source credibility, Medium credibility, Content credibility, Millennials, Pakistan.

\section{ABSTRACT}

This study observed the influence of the credibility factors on the perception of the credibility of political information among the youth. Credibility can be due to the medium through which the information reaches the people; the source of the information; or the information itself. Each of the three factors: medium, source, and message are analyzed separately as an independent variable to observe its influence on the overall credibility of the political content received, as the dependent variable. The key finding is that the majority of them trust that online political content is produced and run by the trustworthy, intelligent and experts. They also appear to believe that online political content is trustworthy, accurate, fair and respectful towards other's privacy. Moreover, it is found that the credibility of online political content is independent of any other credibility factor such as the source, medium, or the content credibility. The number of likes and shares seems to be the biggest criteria of the credibility and trustworthiness of a political content in the eyes of young university students. The findings of the study would allow the experts to convey political information to millennial effectively.

\section{Introduction}

Today, a significant portion of the population of Pakistan which is 36 million is active social media users (Internet World Stats, 2019). Especially for young people in Pakistan internet has become has become the primary media vehicle. It was clearly witnessed in Pakistan during 2018 national elections social media played an important role in informing and organizing youth for political participation. Social networking sites specifically through Facebook, Twitter and YouTube served as the common platform for sharing political updates. The ease and speed of social media empowered citizen journalism allowing consumers to generate their own content attracting youth to politics and contributing in political discourse.

The opportunity to express and share views on political issues has changed the media users' passive attitude towards politics. Social media allows people to engage in politics at psychological and emotional level. The way they receive process and share political information has changed. This active involvement in creating, sharing, disseminating political messages is termed as digital participation. The rise of digital political participation can be attributed to the unresponsive mainstream media and its dwindling credibility among the audience.

Citizen generated content on the internet is generally considered as authentic and truthful news material. The videos, footages, and other information shared by ordinary citizens is assumed to communicate which is not covered in the mainstream media.

The democratic nature of the Internet and boundless space for and amount of information, has created a 'public sphere' which could not be imagined before. The interactive nature of Web 2.0 technology has completely transformed the way information is "created, shared, stored, distributed, and manipulated," (Wolcott, 2007). The advanced media technology allows an average internet user to become a content provider instead of passively consuming what is provided by publishing his or her own content (Abdullah, 2007). There are myriads of apps and options available on the internet which facilitates creative content by the users such as Blogs and independent websites. Another remarkable aspect of the Web 2.0 technology that increases its

K C AL-KINDI CENTER R D FOR RESEARCH AND DEVELOPMENT Your gateway to world-class research

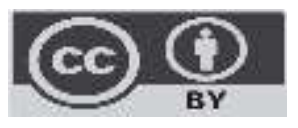

Published by Al-Kindi Center for Research and Development. Copyright (c) the author(s). This open access article is distributed under a Creative Commons Attribution (CC-BY) 4.0 license 
credibility dimension is that it enables people to work jointly in groups without any constraints of time and space on single document or story in a transparent manner as every entry is recorded and can be tracked easily (Wolcott, 2007).

Social Media a term that is used to describe "Web-based tools that harness the power of collaboration and group interaction" such as Facebook, Twitter, YouTube, etc. (Wolcott, 2007). The design of these is extremely user friendly and interactive in nature that allows people with average levels of skill and intellect use it that is why they have become so popular. These social networking sites (SNS) are used to build communities and gather people on common concern issues. These help average citizens to engage in political matters and attracting attention of the government or concerned institutions (Zhuo, Wellman, \& Yu., 2011). Political engagement on the SNS is often deemed as the channel to convey the unheard voices to the high ups (Spaiser, Chadefaux, Donnay, Russmann, \& Helbing, 2017). Blogs are the platforms where people can write or post videos about anything of their interest. Blogs, that is, the content produced by people using free online self-publishing tools. Blogging has played a significant role in intellectually engaging and mobilizing to actively take interest in the politics such as to take part in National elections. Social media have created a public sphere that is contributing a lot towards developing a culture of reasoning and debate thus, creating political awareness among the masses. There are host of studies that support the notion that people find online political information more credible for many reasons such as citizen voice etc.

Therefore, considering the vital role that social media and internet is playing in influencing and mobilizing people for political participation, it is imperative to investigate the factors that contribute to the increasing credibility of an online political news and information as compared to its equivalent mainstream media.

The Credibility, in this study, refers to the perceived believability based on trustworthiness and expertise (Chung, Yoonjae, \& Stefanone., 2012). This paper aims to examine the factors contributing to the credibility perception of online news sources among the young people in comparison to the mainstream media. This study focuses on the different relations between the different factors; the relation between content provider and source of news, as well as transparency, openness and content provider. It is conventional wisdom that transparency and openness of the content provider have proved to be some of the main criteria that a source gets wide public acceptance as mentioned. Questions on expertise, trustworthiness, transparency, and interactivity will be raised in order to gain a fully-fledged view on the matter. In conclusion, Social media outlets offer a platform for otherwise marginalized views, acting as an alternative news source.

In this respect, social media is a topic of interest to all mass media researchers to investigate its dimensions. The linear direct model of sender, message, and receiver then feedback no longer exists, it has become multidimensional in which the receiver has become the sender and feedback has changed to the message. This paradigm shift in the communication model, ignited by social media, has caused myriad advantages as well as disadvantages in the media system. In this study the researcher is particularly interested to investigate the credibility of online political news as one of the constructs that has been affected by this paradigm shift. This study attempts to explore the factors that influence the perception of the credibility of political information among the millennials of Pakistan. The Credibility can be due to the medium through which the information reaches the people; the source of the information; or the information itself. Each of the three factors: medium, source, and message are analyzed separately as an independent variable to observe its influence on the overall credibility of the political content received, as the dependent variable.

\section{Statement of the Problem}

The purpose of this research is to examine how credible the millennial of Pakistan finds the political information they come across on the internet? The millennials refer to the young people born between the years 1981-1996, ranging from the ages of 18-37. The internet here refers to all the most commonly consumed online sources including official news websites of popular news organizations and social networking sites such as Facebook, YouTube, etc. This study aims to investigate the relative significance of source, message and medium in determining the perception of the credibility of online political news. Furthermore, the online media consumption habits of the millennial will be observed in terms of frequency, time spent and dependability. The sample of the study will be obtained from the different areas of Lahore. The objectives and their relevant research questions of the study are:

1. To observe how the millennials use the internet for seeking political information the three relevant research questions are: RQ1a: How much time they spend daily browsing online political news?

RQ1b: How much do they rely on online sources for political information?

RQ1c: Do they rely on specific media platform for political information?

2. To examine how credible millennials perceive online political information two relevant questions are : RQ2a: What is the criterion of credibility of the online political information? 
RQ2b: How millennials perceive online political information in terms of journalistic quality?

3. What is the effect of source, medium and content on the perception of credibility of online political information?

a. How Millennials rate the online source credibility for political information?

b. How Millennials rate the online medium credibility for political information?

c. How Millennials rate the online content credibility for political information?

\section{Research Design and Methodology}

It is a survey based quantitative study. The main objective of this research is to empirically measure the variables involved and check their relationship. As this study is mainly concerned with the perceived credibility of the media out of many credibility scales (Johnson \& Kaye, 1998; Johnson \& Kaye, 2004; Sundar, 1998; Kiousis, 2001; Flanagin \& Metzger, 2007; Gaziano \& McGrath, 1986) designed to investigate its levels of trust and believability the most suitable one Gaziano and McGrath (1986) scale for credibility was selected. It is in 5-point Likert scale ranging from strongly disagrees to strongly agree with neutral as midpoint.

To ensure the validity and reliability of the questionnaire pilot testing was done and the value of Cronbach's Alpha ( $\alpha=.941)$ was observed that confirmed the reliability of the instrument. The variables are conceptualized and operationalized as follows:

\section{A. Online Media Consumption Habits}

The online media consumption habits in this research refer to the patterns and routines in which young people log online per day generally and specifically to seek political information. . Media habits are understood in terms of: (1) frequency of their online log in; (2) time spent online in a typical day; and (3) favorite or most visited media platform. Media platform means a service, site, or medium that delivers media to an audience. It includes social networking sites (e.g., Facebook, ); micro blogging (e.g. Twitter,); photo sharing (e.g. Instagram); video sharing (YouTube, Facebook Live). It is prime function is to deliver but as in social media it sometimes allows for feedback, discussion or sharing.

\section{B. Perceived Credibility of Online political news and information}

To assess the level of perceived credibility of online news and information for political information Gaziano and McGrath (1986) scale was adopted. It includes twelve factors constituting the credibility that are: trustworthiness, currency, bias, fairness, reporting the whole story, objectivity, honesty, up-to-date, believability, balance, accuracy and timeliness and only focusing on online news (Gaziano \& McGrath; 1986). In addition, two more items are added which are specifically concerned with online interactive platforms and take into account the influence of number of 'shares' and 'likes' indicative of credibility of the piece of information or a news story. The perceived credibility of online political news and information is the dependent variable.

\section{Perceived Source Credibility}

The Perceived source credibility refers to the trust or believability an individual holds for the particular source. In this study the perceived source credibility is measured in terms of the three aspects of the source characteristics: expert or amateur; intelligent or unintelligent; trustworthy or not trustworthy. The respondents were asked to rate each aspect on the semantic scale of 1 to 5 with 1 being the minimum.

\section{Perceived Medium Credibility}

Perceived source credibility is the trust an individual holds for the particular medium. It refers to the trust and reliance of an individual on that particular source for getting political information because of the associated perceived characteristics. In this study the perceived medium credibility is measured in terms of the seven characteristics associated with the medium credibility are: accuracy, trustworthiness, responsibility, objectivity, care for audiences' needs and interest, dynamic, and open mindedness. The respondents were asked to rate each characteristic on the scale of 1-5 with 1 being the minimum.

\section{E. Perceived Message Credibility}

The perceived message credibility is the trust or believability an individual holds for the truthfulness of the message received. In this study it refers to the perception of the audience that the content or message upholds the four fundamental conditions of a good message that is trustworthiness, accuracy, fairness, and respecting people's privacy. The respondents were asked to rate the criteria on which he or she evaluates content or message credibility in general. The rating will be on the scale 1-5, with 1 being the minimum, to indicate the degree to which respondents think that message can be trusted or cannot be trusted; it is fair or unfair; accurate or inaccurate; and it respects the peoples' privacy or do not respect the peoples' privacy.

\section{F. Demographical variables}

The demographic information of the respondents in this study includes the age, gender, education level, family income level, and place of residence i.e., urban or rural. 


\section{Data Analysis and Findings}

The data was gathered from various universities of Lahore and the students approached for the survey fulfilled the condition of being millennial (born between 1981 and 1996 and in 2020 they are 24 to 39 years old). The descriptive statistics of the respondents is shown in Table 1 . The income groups were roughly distributed equally across the sample as one third of each group: low, medium and high income. Representative of all academic disciplines were included in the sample, although the analysis later showed that there is no significant difference among them. It was found that gender, age and academic discipline does play any considerable role in the perception of the credibility of online political information.

Table 1: Descriptive Statistics of the respondents $N=300$

\begin{tabular}{lll}
\hline \multicolumn{1}{c}{ Variable } & Frequency & Percent (N=315) \\
\hline Gender & & \\
Male & 144 & 45.7 \\
Female & 171 & 54.3 \\
Education & & \\
Undergraduate & 236 & 58.8 \\
Post graduate & 65 & 21.6 \\
& & \\
Academic Discipline & & \\
Social Science & 47 & 16.2 \\
Natural Science & 98 & 33.7 \\
Business Studies & 20 & 6.9 \\
Humanities & 15 & 5.1 \\
Computer Science & 75 & 25.8 \\
Law & 36 & 4.5 \\
& & \\
Family Income & 88 & 26.2 \\
Up to 75000 & 107 & 35.9 \\
Rs.76000- 99000 & 113 & 37.9 \\
Rs.1 lac or above & & \\
Age & 271 & 87.4 \\
24 - 25 & 39 & 12.6 \\
26 - 35 & & \\
& & \\
\hline
\end{tabular}

RQ 1a: How much time they spend daily browsing online political news?

The millennials reported that they remain online most of the time. The reason was that they access internet from their cell phones so in a way they remain login on all their frequent sites 24/7.

RQ1b: How much they rely on online sources for political information?

The data shows (Fig 1) that the most frequently visited three internet places for political news and information are YouTube, Facebook and Google respectively. Instagram and Twitter come after them. Blogs and other sites such as newspapers and TV channel websites are not very frequently visited by the university students who were the survey respondents.

RQ1c: What are the most preferred media for getting political information?

The data further shows (Fig. 2 ) that the most preferred sites for obtaining political news and information among the university students YouTube and Facebook followed by Google and Twitter respectively. Television, newspapers and blogs come after YouTube and Facebook. It appears that students are not interested in getting the political news directly from the news agencies and other traditionally considered authentic news sources. Students rather get their information from secondary sources such as from the YouTube videos and Facebook pages. The bar graphs in this analysis represent the percentage of the variables. 


\section{Frequently Visited Sites}

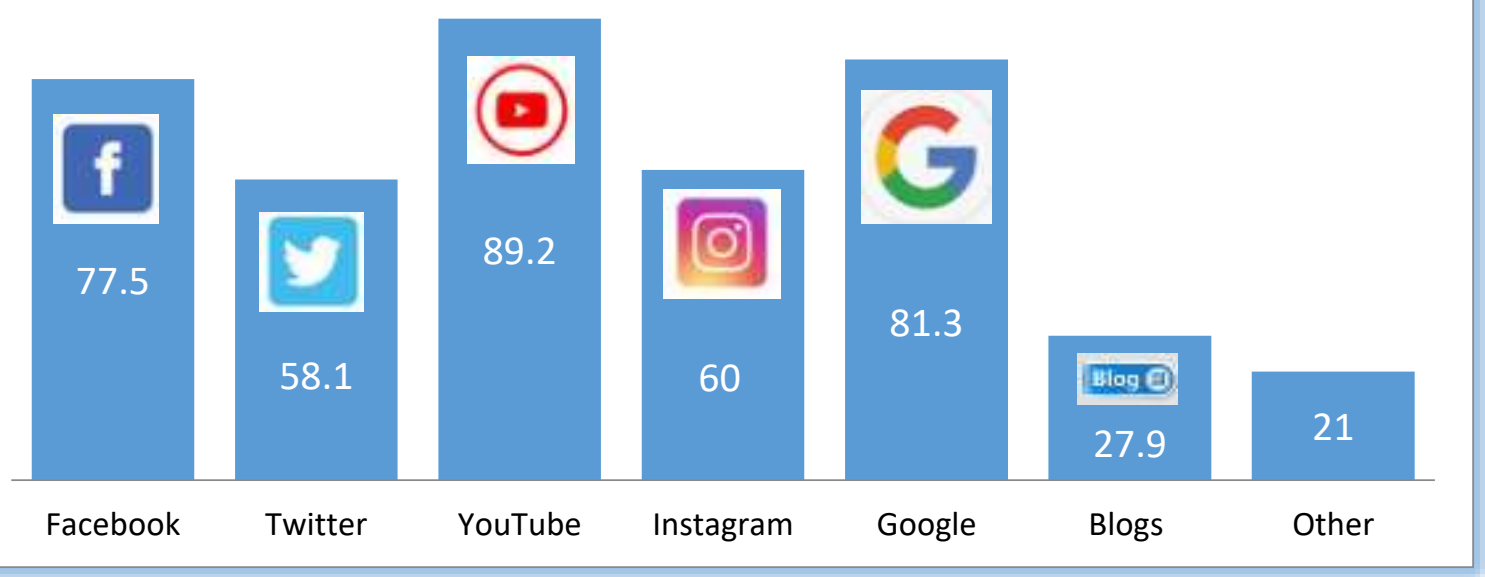

Figure 1: Most frequently visited sites among the university students

\section{Online Sites Prefered for Political News \& Information}

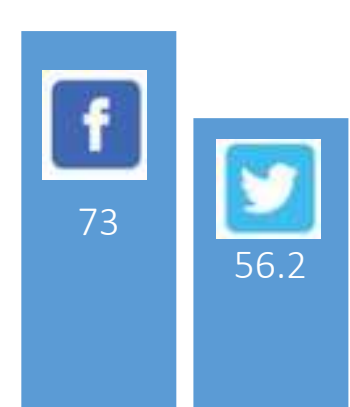

Facebook

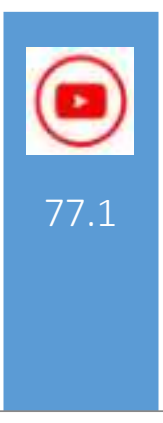

YouTube

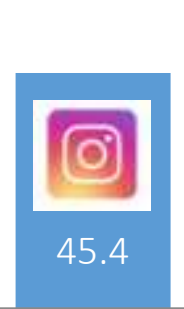

Instagram

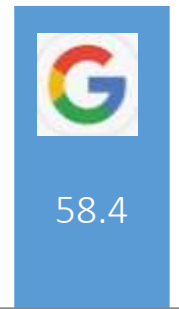

Google

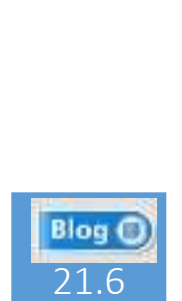

Blogs

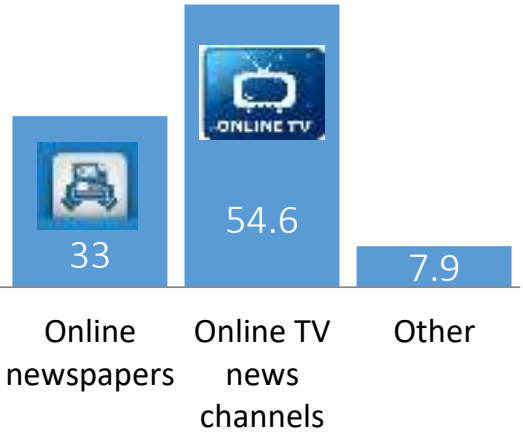

Figure 2: Most preferred online sites for getting online political news and information among the university students

Likes and Shares as a Credibility Indicator

$R Q 2 a$ : What is the criterion of the credibility of the online political information?

Credibility criteria of the respondents found to be linked to the numbers of likes and shares content gets from the users (Fig. 3 ). The students who clearly disagreed with the notion of more likes and more shares mean the content made up only one fifth of the whole. The respondents who believed that likes and shares reflect the credibility of the content were almost same as those who were indecisive, implying that they are not rejecting the idea that likes and shares means authentic truthful content. So it may be assumed that approximately half of the students believe that the number of likes and shares mean the information provided in the content is true and can be taken as credible. 


\section{Online News Credibility Criteria}

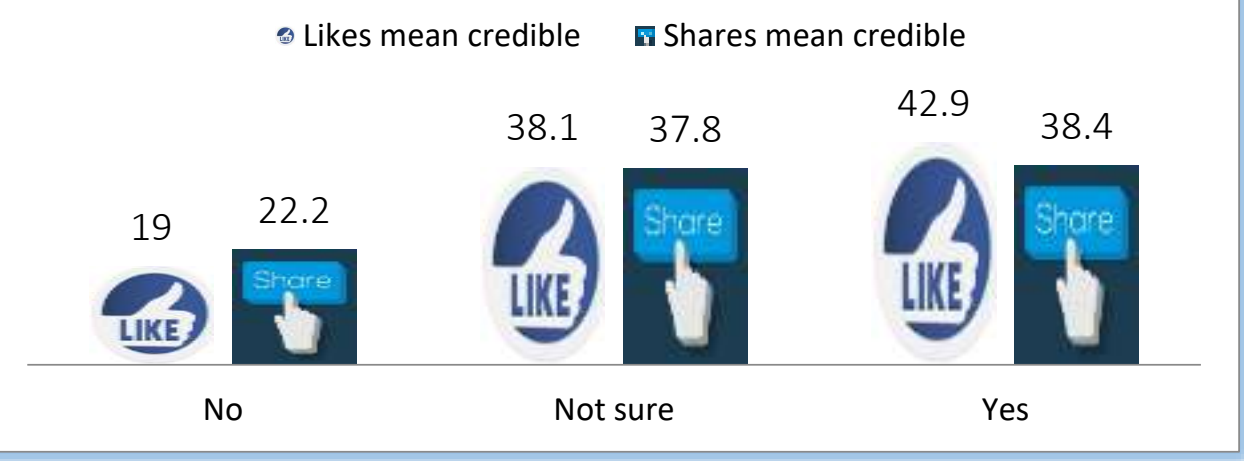

Figure 3: The students' perception of the number of 'Likes" and "Shares" as the measure of Credibility of the online political content

Online Political News Credibility

RQ2b: Do millennials perceive online political information as credible in terms of journalistic quality?

The overall perception among the millennia of how credible the political news and information present on various websites was assessed for the twelve journalistic aspects. The graph shows that majority of the students voted for sure consider online political content up to date, current and timely (Fig.4). Further, the same believe that the online news is balanced, accurate, trustworthy, and fair respectively. One third chose 'sure' for believable, unbiased, objective, and reporting the whole story. The least number of respondents seem to trust that the political content online is honest. Data revealed that for political content as being honest and reported the whole story were the two dimensions for which largest number of 'not at all' was opted.

\section{Online Political News Credibility Perception}

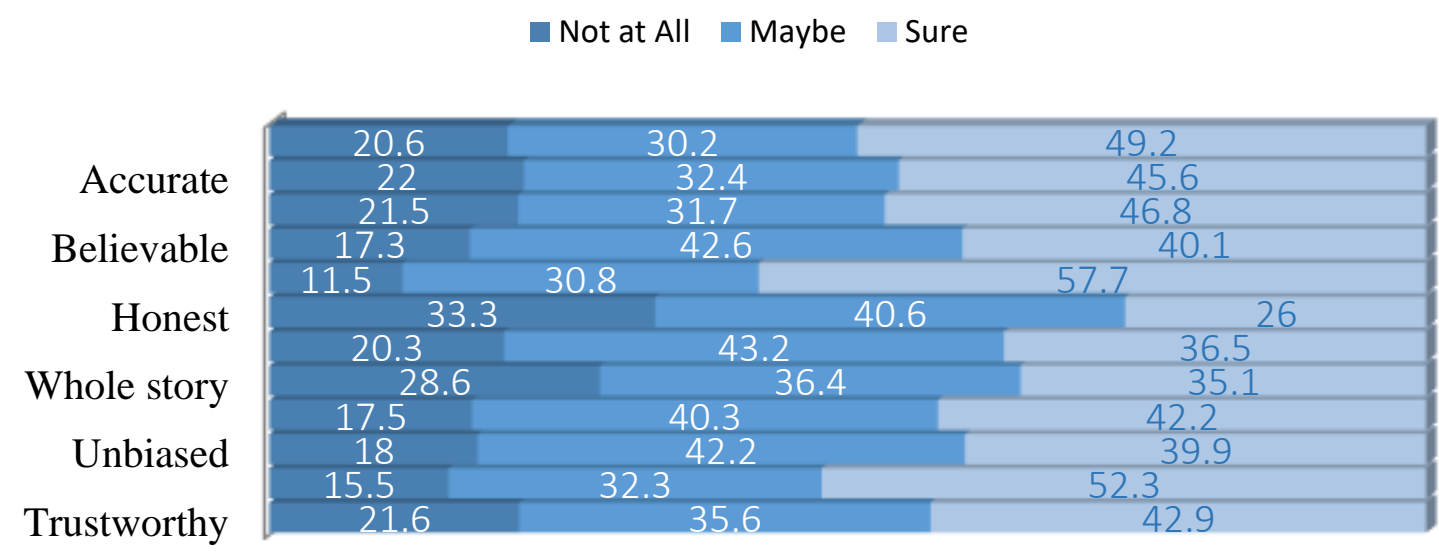

Figure 4: Students' perception of the online political news and information credibility through twelve journalistic aspects

RQ3a: How Millennials rate the online source credibility for political information?

Online Source Credibility

The source credibility is one of the three dimensions of the credibility. The three aspects of the credibility of a source are measured in terms of expertise, intelligence, and trustworthiness. Figure 5 shows that two fifth of the population is confident that they consider online sources of political news and information are expert, intelligent, and trustworthy. One fifth of the respondents believe that the sources producing political content online are generally amateur, unintelligent, and untrustworthy. 
One third of the respondents seem to be undecided about it, but it can be assumed that they may consider the online sources positively for expertise, intelligence, and trustworthiness.

\section{Online Source Credibility}

\begin{tabular}{|c|c|c|c|}
\hline Trustworthy & 18.5 & 33.2 & 48.3 \\
\hline Intelligent & 22.0 & 32.5 & 45.5 \\
\hline Expert & 20.3 & 34.8 & 44.8 \\
\hline
\end{tabular}

Figure 5: The students' percentage graph of Source Credibility of the online political content in terms of Expertise, Intelligence, and Trustworthiness

RQ3b: How Millennials rate online medium credibility for political information?

Online Medium Credibility

The credibility of the medium through which political content is received was measured by asking the opinions of the respondents against seven aspects (Fig 6). More than half of the respondents believe that the political content found on online media is open minded, trustworthy, takes care of the audiences' interests, and accurate. Further nearly half of the rest feel that online media is dynamic, responsible, and objective, respectively. One fifth of the respondents were of the opinion that online media political content is mostly static, subjective, not trustworthy, and does not care about the interests of the readers or audiences. The same group also believed that the online media is inaccurate, irresponsible, and close minded.

\section{Online Medium Credibility}

\begin{tabular}{|c|c|c|c|}
\hline & Not at & Maybe & \\
\hline Open minded & 17.7 & 26.1 & 56.2 \\
\hline Dynamic & 25.5 & 25.5 & 49.3 \\
\hline Care for public interest & 19.1 & 29.3 & 51.6 \\
\hline Objective & 20.3 & 37.1 & 42.7 \\
\hline Responsible & 18.5 & 36 & 45.5 \\
\hline Trustworthy & 19.8 & 25.4 & 54.8 \\
\hline Accurate & 18.6 & 30.5 & 50.9 \\
\hline
\end{tabular}

Figure 6: The students' percentage graph of Medium Credibility indicators for the online political content.

The Online Medium Credibility turned out to be high among the university students. Half of the students seem to believe the online media as highly credible. One third was not out rightly doubting the credibility they were not sure and opted for maybe sometimes. Only a bit more than ten percent altogether rejected the credibility of the online media. 
$R$ Q3c: How Millennials rate online content credibility for political information?

Online Content Credibility

The third dimension of the media credibility is content credibility. The students were asked for their opinion about how much they find the online political content credible. The credibility was assessed in terms of Accuracy, trustworthiness, respect for others' privacy and fairness (Fig 7).

\section{Online Content Credibility}

\begin{tabular}{r|ccc} 
& \multicolumn{3}{c}{ Not at all } \\
& \multicolumn{4}{c}{ Maybe } & Sure \\
Accurate & 19.9 & 39.5 & 40.6 \\
\cline { 2 - 4 } Trustworthy & 20.1 & 34.6 & 45.2 \\
\cline { 2 - 4 } Respects privacy & 27.5 & 25.4 & 47.2 \\
\cline { 2 - 4 } Fair & 28.8 & 25.6 & 45.6
\end{tabular}

Figure 7: The students' perception graph of online political content credibility indicators

Two fifth of the respondents seemed to believe that online content cares and respects the privacy of others. They also believe that the online political content is often fair and can be trusted. One third of the respondents appear to be unsure of the accuracy and trustworthiness of the content. Furthermore, slightly less than those doubts the fairness of the content and was not sure whether online media content respects the privacy of others. One third of the students consider the online political content as unfair and violating others' privacy. One fifth is of the opinion that online political content is neither trustworthy nor accurate.

For getting the clearer idea of the credibility of the internet in relation to the political content all the four dimensions were consolidated to create in a single variable, respectively. The reliability of the variable was confirmed by calculating their respective Cronbach's alpha values as described in the Table 2. Each credibility variable was observed for the mean values of credibility level low, medium, and high.

It was found that one third of the respondents consider the online political news and information as highly credible. Two fifth are not out rightly rejecting the credibility of the political news but they are also not sure. One fifth of the respondents clearly believe that online political news is not credible. Furthermore, almost half of the respondents seem to trust online sources for the political news and information and rate them as credible. The result demonstrated that for majority of the students' online content credibility appear quite high, that is almost fifty percent. Only around twenty percent of the students seem to doubt the credibility. The Online Medium Credibility turned out to be high among the university students. Half of the students seem to believe the online media as highly credible. One third was not completely seemed to doubt the credibility; they were not sure and opted for maybe sometimes. Only a tiny percentage rejected the credibility of the online media.

Table 2 : Mean scores of the credibility variables

\begin{tabular}{lllll}
\hline & $\alpha$ & Low & Medium & High \\
\hline Online News Credibility & .941 & 20.3 & 43.4 & 36.3 \\
Source Credibility & .820 & 18.7 & 47.2 & 34.2 \\
Content Credibility & .841 & 19.3 & 35.4 & 45.3 \\
Medium Credibility & .852 & 11.2 & 37.7 & 51.1 \\
\hline
\end{tabular}


Table 3: Descriptive statistics of the credibility variables

\begin{tabular}{lccc}
\hline & $\mathrm{N}$ & Mean & SD \\
\hline Medium Credibility & 315 & 2.40 & 0.68 \\
Content Credibility & 315 & 2.26 & 0.76 \\
Source Credibility & 315 & 2.15 & 0.71 \\
Online News Credibility & 315 & 1.93 & 0.64 \\
\hline
\end{tabular}

One way ANOVA was conducted to compare the effect of three credibility dimensions on the credibility of online political content. The analysis of variance showed that there is no significant effect of the three credibility variables on the credibility of online political news and information remain independent of source, $F(2,315)=1.63, p=.019 ;$ medium, $F(2,315)=2.01, p=$ .136 ; and content credibility, $\mathrm{F}(2,315)=.068, \mathrm{p}=.068$.

Table 4: The results of analysis of variance (One-way ANOVA) for the differences in the impact on online political content credibility of the three credibility dimensions.

\begin{tabular}{llllll}
\hline & Sum of Squares & df & Mean Square & Fig. \\
\hline Source Credibility & 1.66 & 2 & .83 & 1.63 & .197 \\
Medium Credibility & 1.94 & 2 & .97 & .136 \\
Content Credibility & 3.09 & 2 & 1.55 & 2.72 \\
\hline
\end{tabular}

\section{Conclusion}

It is concluded that the millennials, that constitute the senior university students of Pakistan are heavy users of online media. They access internet mostly from their mobile phones and remained logged in for most of the time. YouTube and Google are the most preferred sites for getting updated and receiving political news and political information. Facebook comes at the third in priority sequence. The majority of them trust that online political content is produced and run by the trustworthy, intelligent and experts. They also appear to believe that online political content is trustworthy, accurate, fair and respectful towards other's privacy. Moreover, it is found that the credibility of online political content is independent of any other credibility factor such as source, medium, or content credibility. The number of likes and shares seems to be the biggest criteria of credibility and trustworthiness of a political content in the eyes of young university students.

\subsection{Limitations of the study}

The sample selected for the study was only the university students which do not represent all the other millennials who are not in the higher education but are avid consumers of news media.

\subsection{Suggestions for Future Research}

Similar studies with a bigger sample size and greater demographic and geographic diversity would help in fully understanding the extent of media credibility and the different forms it takes among the millennials. 


\section{References}

[1] Chung, J. C., Yoonjae, N., \& Stefanone., M. A. (2012). Exploring Online News Credibility: The Relative Influence of Traditional and Technological Factors. Journal of Computer Mediated Communication, 17(2), 171-186 https://doi.org/10.1111/j.1083-6101.2011.01565.x.

[2] Flanagin, A. J., \& Metzger, M. J. (2007). The Role of Site Features, User Attributes, and Information Verification Behaviors on the Perceived Credibility of Web-based Information. New Media and Society, 9(2), 319-342 https://doi.org/10.1177/1461444807075015.

[3] Gaziano, C., \& McGrath, K. (1986). Measuring the concept of credibility. Journalism Quarterly, 63, 451-462 https://doi.org/10.1177/107769908606300301.

[4] Johnson, T. J., \& Kaye, B. K. (1998). Cruising is Believing? Comparing Internet and Traditional Sources on Media Credibility Measures. Journalism \& Mass Communication Quarterly, 75(2), 325-340 http://www.aejmc.org/home/wp-content/uploads/2012/09/Journalism-MassCommunication-Quarterly-1998-JohnsonKay-325-340.pdf.

[5] Johnson, T. J., \& Kaye, B. K. (2004). Wag the Blog: How Reliance on Traditional Media and the Internet Influence Credibility Perceptions of Weblogs among Blog Users. Journalism and mass communication quarterly, 81(3), 622-642 https://doi.org/10.1177/107769900408100310.

[6] Kiousis, S. (2001). Public Trust or Mistrust? Perceptions of Media Credibility in the Information Age. Mass Communication and Society, 4(4), 381-403 https://doi.org/10.1207/S15327825MCS0404_4.

[7] Spaiser, V., Chadefaux, T., Donnay, K., Russmann, F., \& Helbing, D. (2017). Communication power struggles on social media: A case study of the 2011-12 Russian protests. Journal of Information Technology \& Politics, 14:2, 132-153.

[8] Sundar, S. (1998). Effect of Source Attribution on Perception of Online News Stories. Journalism \& Mass Communication Quarterly, 75(1), pp 55-68 https://doi.org/10.1080/19331681.2017.1308288.

[9] Wolcott, M. (2007). What Is Web 2.0? Retrieved 6 14, 2019, from http://www.cbsnews.com/news/what-is-web-20/

[10] Zhuo, X., Wellman, B., \& Yu., J. (2011). Egypt: The First Internet Revolt? pp. 6-10 